\title{
First Hyperpolarizabilities of Nonlinear Optical Compounds: Susceptibility in Donor-Acceptor Stilbene Analogs
}

\author{
Gyoosoon Park, Woo Sik Jung, and Choon Sup Ra ${ }^{\frac{b}{v^{*}}}$ \\ Department of Chemistry, Kookmin Liniversity: Seoul /36-702, Korea \\ ${ }^{\dagger}$ School of Chemical Engineering and Technolog;, Yeungnam Lniversity, Gyongsan 712-7f9, Korea \\ $\$$ Department of Chemistry and Institute of Natural Science, Yeungnam Hniversity, Gyongsan 712-749, Korea \\ Received.tine 18,2004
}

Key Words : Nonlinear optical, Hyperpolarizability, Susceptibility, I Jeteroaromatics, Stilbene

The nonlinear optical (NI.O) responses induced in various materials are of great interest in recent years because of the potential applications in photonic technologies such as optical communications, computing and data storage, and image processing ${ }^{1-5}$ The design and synthesis of optimized molecules is the key step in this area of research. Recent efforts have been focused to develop organic molecules with large molecular nonlinear optical (NI.O) response ( $\beta$. first hyperpolarizability), improved optical transparency, and good themal stability. Most investigated chromophores for NLO applications are conjugated bridges such as substituted polyenes and polyynes endeapped with strong donor and acceptor groups. Incorporation of aromatic rings into the push-pull polyenes like substituted stilbenes enhances thermal stability, but decrease molecular hyperpolarizability. ${ }^{6}$ Recent studies have shown that replacement of the aromatic rings with more easily delocalizable 5-membered heteroaromaties such as thiophene, furan and pyrrole results in an enhanced molecular hyperpolarizability. ${ }^{7}$ Theoretical sludies of several 5-membered heteroaromatic donoracceptor stilbene analogs have shown that heteroaromatics enhance values by several factors: i) the electron density of the ring systems, ${ }^{8}$ ii) the electron poor and rich nature of the ring systems. ${ }^{8.1}$ iii) the relative orientation of the heteroaromatic ring. ${ }^{(t)}$ Though these results may explain several aspects of the molecular enhancement in those NL.O chromophores, the comprehensive account on the cuantitative structure-property relationships that can be readily served as a guideline in designing optimal NLO chromophores is still lacking. In this work, we studied the lirst hyperpolarizabilities of various heteroaromatic as well as aromatic ring analogs of donor-acceptor stilbenes 1-12 (as shown in Figure 1) by the ab initio method. The ellects by modifying the conjugated bridges and tuning the donor/ acceptor groups of the conjugated bridges on the lirst hyperpolalizabilties were investigated.

Computation method. All molecules fully optimized at I Iar1ree-Fock level using the $6-31 \mathrm{G}$ basis set in the Gaussiom 98 program" show almost planar structures. The tensor components of the static first hyperpolarizabilities $(\beta)$ were analytically calculated by using the coupled perturbed I lartec-Fock (CPIF) method. The intrinsic hyperpolarizability $\mid \beta \|$ is given by magnitude of the vector component of the hyperpolarizability $(\beta) ;\|\beta\|-\left({ }^{2}{ }^{2}{ }_{y}{ }^{2} 1_{z}{ }^{2}\right)^{1 / 2}$, where $x=$ ? and ${ }_{L}$ are the vector components of the hyperpolarizability tensor in the direction of the $x, y$ and $z$ molecular axis, respectively. The calculated values were converted into electrostatic units ( 1 a.u. $-8.6398 \times 10^{33}$ esu). The values of the first hyperpolarizabilities $(\beta)$ and susceptibility $(\rho)$ are summarized in Table 1.

\section{Results and Discussion}

Calculations are made on various structures shown in Figure 1, where one end of the conjugated bridge has a nitro group and the other end is substituted with a variety of
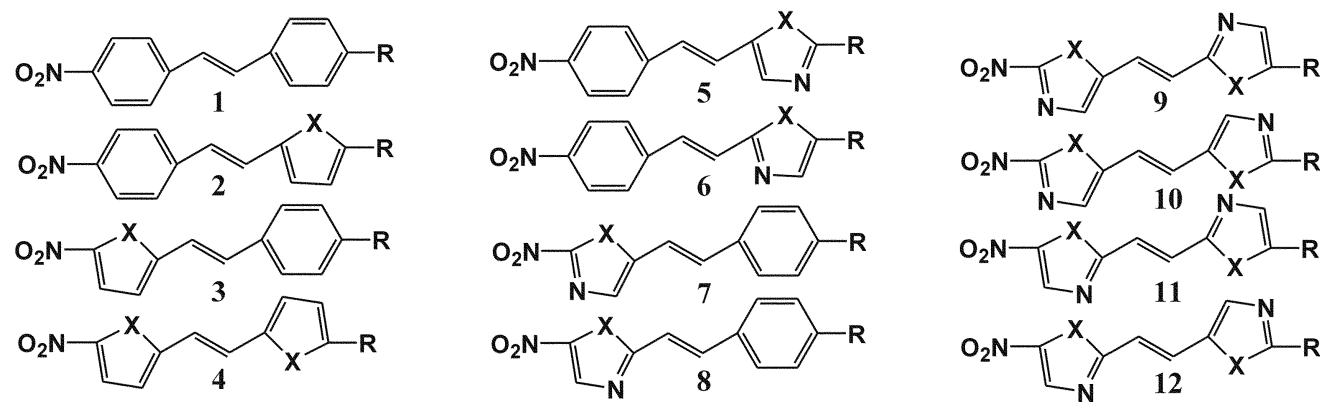

(R H. Me. Oh. OMe. NH. N.Mes: X O.S)

Figure 1. Nromatic and heteroaromatic stilbene analogs.

Corresponding Author. e-mail: csräay.uackr 
Table 1. The calculated values"

\begin{tabular}{|c|c|c|c|c|c|c|c|}
\hline $\begin{array}{c}\mathrm{nX} \\
(\mathrm{X}=\mathbf{O}, \mathrm{S})\end{array}$ & $\begin{array}{c}\mathrm{R}=\mathrm{H} \\
(0.00)^{\circ}\end{array}$ & $\begin{array}{l}\mathrm{R}=\mathrm{Mc} \\
(-0.33)^{\prime}\end{array}$ & $\begin{array}{c}\mathrm{R}=\mathrm{OH} \\
(-0.55)^{\circ}\end{array}$ & $\begin{array}{l}\mathrm{R}=\mathrm{OML} \\
(-0.80)^{\prime}\end{array}$ & $\begin{array}{l}\mathrm{R}=\mathrm{NH}_{2} \\
(-1.19)^{\prime}\end{array}$ & $\begin{array}{l}\mathrm{R}=\mathrm{NM \textrm {C } _ { 2 }} \\
(-1.73)^{\prime \prime}\end{array}$ & $\rho^{\prime \prime}$ \\
\hline 1 & 21.8 & 27.7 & 31.4 & 35.5 & 51.6 & 6.3 .1 & -24.93 \\
\hline 20 & 29.1 & 37.0 & 40.6 & 47.0 & 63.5 & 78.3 & -29.28 \\
\hline 30 & 25.1 & 31.5 & 34.8 & 39.4 & 55.4 & 68.0 & -25.72 \\
\hline 40 & 29.9 & 38.3 & 42.5 & 49.4 & 65.0 & 81.9 & -30.62 \\
\hline $2 S$ & 21.0 & 26.6 & 28.9 & 35.3 & 50.9 & 66.7 & -27.41 \\
\hline $3 S$ & 27.8 & 35.4 & 38.8 & 43.6 & 65.0 & 80.6 & -31.77 \\
\hline $4 S$ & 27.3 & 34.8 & 38.7 & 46.8 & 66.8 & 90.2 & -37.35 \\
\hline 50 & 19.5 & 24.3 & 24.8 & 28.7 & 38.6 & 50.8 & -18.26 \\
\hline 60 & 16.2 & 20.9 & 22.6 & 26.0 & 38.3 & 47.0 & -18.57 \\
\hline $5 S$ & 16.8 & 21.5 & 24.0 & 27.9 & 39.1 & 52.7 & -21.09 \\
\hline $6 S$ & 13.9 & 18.6 & 21.5 & 25.1 & 39.6 & 52.7 & -23.24 \\
\hline 70 & 24.3 & 30.7 & 34.0 & 38.6 & 54.2 & 67.1 & -25.58 \\
\hline 80 & 24.8 & 31.7 & 35.2 & 40.0 & 5600 & 70.2 & -26.99 \\
\hline $7 S$ & 24.4 & 31.6 & 34.9 & 39.9 & 58.4 & 72.8 & -29.02 \\
\hline $8 S$ & 33.0 & 42.1 & 46.0 & 52.5 & 73.4 & 92.2 & -35.16 \\
\hline 90 & 17.0 & 22.6 & 24.7 & 28.5 & 42.3 & 54.8 & -22.44 \\
\hline 100 & 19.1 & 24.6 & 25.9 & 30.2 & 40.9 & 56.3 & -21.49 \\
\hline 110 & 17.7 & 23.8 & 26.0 & 30.3 & 45.2 & 600 & -25.00 \\
\hline 120 & 19.6 & 25.4 & 26.6 & 31.2 & 42.2 & 58.6 & -22.48 \\
\hline $9 \mathrm{~S}$ & 16.7 & 21.9 & 24.6 & 28.4 & 44.2 & 60.4 & -25.93 \\
\hline IOS & 15.2 & 19.5 & 21.2 & 24.8 & 35.8 & 51.3 & -21.02 \\
\hline IIS & 21.7 & 28.7 & 31.9 & 37.1 & 57.8 & 80.2 & -34.59 \\
\hline $12 S$ & 23.6 & 28.6 & 31.5 & 39.4 & 54.6 & 76.7 & -31.50 \\
\hline
\end{tabular}

"Init of $\beta$ is $10^{-300} \mathrm{esu}$. "Avarage slope of $\beta$ against $\sigma^{\prime}$. "Sec reft. 13.

substituents (i.e., $\mathrm{R}=\mathrm{H}, \mathrm{Me}, \mathrm{OH}, \mathrm{OMe}, \mathrm{NH}_{2}, \mathrm{NMe}_{2}$ ). There are 138 chromophores, which are categorized into three classes (A, B, and C). Class A stands for stilbene series (1). Class B is for stilbene analogs with furan or thiophene (2-4). Class $\mathrm{C}$ is for oxazole or thiazole analogs of stilbene (5-12). Here the stilbene series 1 was chosen as the representative system for comparing $\beta$ values with other classes.

Dependence of on the substituents. The nature of the $\pi$ conjugation in NLO molecules is altered by the electrondonating/accepting ability of the substituents located at the ends of $\pi$-conjugated bridges and thereby the charge transfer within the $\pi$-conjugating pathway and the molecular nonlinearity would be affected. In all chromophores investigated, values increase with the electron-donating ability by the order of $\mathrm{NMe}_{2}>\mathrm{NH}_{2}>\mathrm{OMe}>\mathrm{OH}>\mathrm{Me}>\mathrm{H}$ without an exception. ${ }^{12}$ It shows a good linear correlation between $\beta$ and substituent constants $\left(\sigma_{\text {ats }}{ }^{+}\right)$as reported in literature before. ${ }^{12,14}$

Heteroaromatic effect (Class B). Within the same substituted pattern at the ends of the aromatic/heteroaromatic rings, the magnitude of the value increase depends strongly on both the nature of conjugated bridges and its
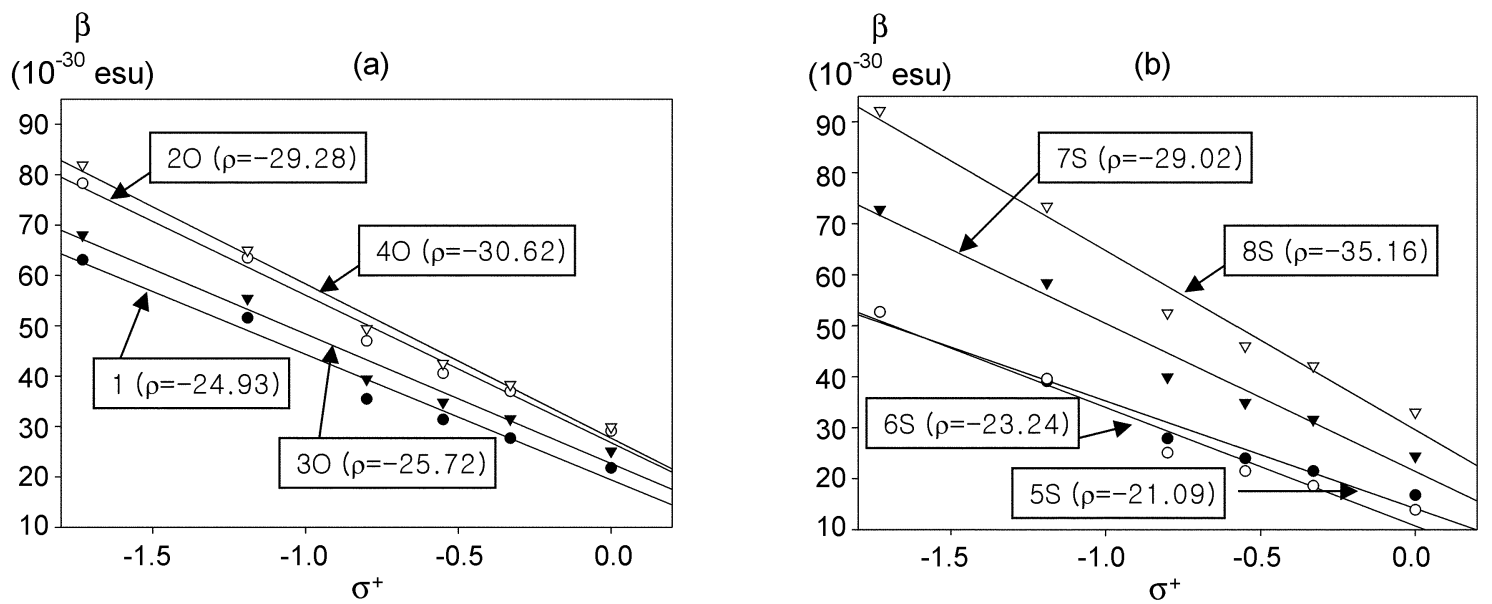

Figure 2. Plot of $\beta$ against substituent constants $(\sigma)$. 


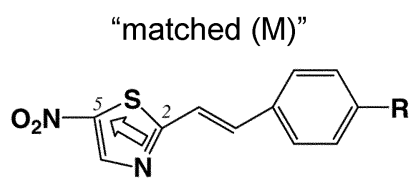

$\mathbf{8 S}$
$\rho=35.16$

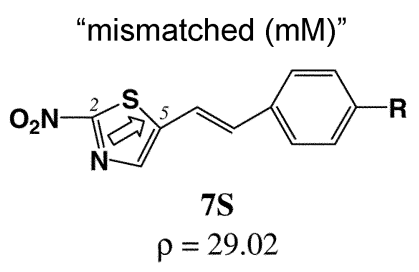

Figure 3. Marched and mismatched pattern in $7 \mathrm{~S} / \mathbf{8 S}$.

position. While the replacement of the benzene ring on the donor end with 5-membered heteroaromatic rings with one heteroatom results in higher values $(2 \sim 4>1)$, the substitution on the acceptor end with heteroaromatics lowers the activity $(2>3)$. The calculated reaches the maximum when the systems have two heteroaromatic rings with one heteroatom at both the donor and acceptor end $(\mathbf{4}>\mathbf{2}>\mathbf{3})$, and this tendency is clearly manifested in the $r$ values as shown in lable 1 and Figure $2 \mathrm{a}$ (the $\mathrm{r}$ value: for $40 ; 30.62 .20 ; 29.28$, $30 ; 25.72)$.

Effect of the substituting pattern (Class C). The tendency of favoring a 1.3-heteroaromatics in the acceptor end to obtain a higher value is observed $(7,8>5,6)$. The substitution pattern is also an another important factor to control the activity. For $7 \mathbf{S} v \mathrm{~s} .8 \mathrm{~S}$, the positioning of nitro group at 5-position of 1,3-thiazole ring rather than 2-position shows higher value for both of $\beta$ and $\rho$ ( $\rho$ value: $\mathbf{8 S}(35.16)>$ $7 \mathbf{S}(29.02)$ ), see Figure $2 \mathrm{~b})$. Similar trend is also shown in oxazole system ( $\rho$ value: $80(26.99)>70(25.58))$. These results can be explained in terms of 'matched' and 'mismatched' property from our previous analysis. ${ }^{15}$. The values reaches a maximum when the direction of the dipole moment of the 1,3-heteroaromatic unit is matched with the direction from donor to acceptor in chromophores (see Figure 3). For chromophores having two heteroaromatic rings (9-12), the substituting pattern notably affects $\beta$ values. In series of molecules with the same donating pattern, compounds with the nitrothiazole ring at the 5-position has a higher value than those at the 2-position $(\mathbf{1 1}>\mathbf{9} ; \mathbf{1 2}>\mathbf{1 0})$. Also these trends are clearly notable in their $\mathrm{r}$ values $(\mathbf{1 1 0}$ $(25.00)>90(22.44) ; 11 \mathrm{~S}(34.59)>9 \mathrm{~S}(25.93) ; 120(22.48)$ $>100(21.49)$ : $12 \mathrm{~S}(31.50)>10 \mathrm{~S}(21.02))$.

In summary, we have investigated the first hyperpolarizabilities of 138 chromophores (1-12)---stilbene and heteroaromatic analogs---by $a b$ initio method. The results reveal a good linear relationship exists between the first hyperpolarizability $(\beta)$ and gas-phase substituent constants $\left(\sigma_{\text {tus }}\right)$ as known before. The susceptibility $(\rho)$ of the $\beta$ to the donor strength is found to be quite characteristic of the conjugated bridges. Our results provides a systematic account of the nature of the heteroaromatics and the substitution pattern at the conjugated bridges on molecular hyperpolarizability of donor-acceptor stilbene chromophores and suggests a practical guideline for developing heteroaromatic NLO materials.

Acknowledgment. This work was supported by Yeungnam University (Grant No. 106117) and Kookmin University (Grant No. 2004303-1).

\section{References}

1. Parasad. P. N.: Williams. D. I. Introdetetion to Nonlinear Opticat Effects in Wolecules and Polymers: John Wiley \& Sons: Vew York, 1991

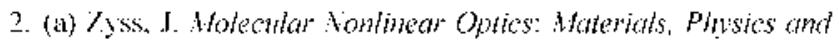
Devices: Academic P'ress: Boston. 1993. (b) Nalwa H. S.. Miyata. S. Eds. Fonlineer Optics of Onganic Holecules and Polvmers: CRC. PJess: Boca Ratotl. FL. 1997

3. Varder. S. R.: Kippelen. B.: Mn, A. K.-Y.: Peyghambarian, V. Satme 1997. 388.845 .

4. Shi, Y. Zhang C.: Bechtel, I. II.: Dalton. I. R.: Robinsom, [3. H.: Steier. W. H. Scienc'e 2000). 288.119.

5. (a) Zhang. Y.: Burzynski. R.: Ghosal. S.: Casstsvens. M. K. Adv. Wtter 1996. 8. 111. (b) Dalton. L. R.: Stcicr. W. H.: Robinson. B. Il.: Thang. C.: Ren, A.: Garner, S.: Chen, $A .:$ I.onderean, T.: Invin, 1.: Carlson. B.: Fifield. L.: Phelan, (i.: Kincaid. C.. Amend. J. Jen, A. J Mater Chem. 1999. 9. 1905. (c) Kajyar, [.: I.ee. K. S. Ien. A. K.-Y. Idv. Polym. Sci. 2003. $16 / .1$.

6. (a) Singer. K. [D.: Sohn. J. E.: King. L. A.: Gorden. H. M.: Katz. H. E.: Dirk. C. W. J. Opt Soc Am. B 1989. 6. 1339. (b) Cheng. L. -T.: Tam, W: Stevenson. S. II.: Meredith. (i, R.: Rikiken, G.: Marder. S. R. J. Phns. Chem. 1991. 95. I063I. (c) Cheng. I. I.: Tam. W.: Marder. S. R.: Stejgman. A. I ... Rikken. (i.: Spangler. C. W. J. Phys. (hem. 1991. 95. 10643.

7. (a) Rao. V. P.: Jen. A. K.-Y.: Wong. K. Y.: Drost. K. I. Tetrahedron Lett. 1993. 34. 1747, (b) Jen. A. K.-Y.: Cai. Y. M.: Bedworth. P. V.: Marder. S. R. Adv Woter. 1997. 9. 132. (c) Cho, B. R.: Son. K. N.: I.e. S. J.: Kang. I. I.: Ilan. M. S.: Jeon, S....: Song. N. W.: Kim. D. Tetrahedron Lett. 1998, 39, 3167. (d) Song. S.: I.ee. S. J.: Cho. B. R.: Shin. D.-H.: Park. K. H.: Lee. C. J.: Kin. N. (hent. Watter. 1999. /1. 1406. (c) Shu. C.-F.: Wang. Y. K. J. Weter (hem. 1998. 8. 833. (f) Brasselet. S.: Cherioux. F.: Audcbert. P.: Zyss. I. Chem. Water. 1999. 1/. 1915.

8. Varanasi. P. R.: Jen. A. K.-Y.: Chandralsekluar. J.: Namboothiri. I. V. N.: Rathua A. J Am. Chem. Soc. 1996. //S. 12443.

9. Albert. I. D. L.: Marks I. J.: Ratner. M. A. J. Am. Chen. Soc. 1997. 119.6575 .

10. Breitung. E. M.: Shu. C.-F.: McMahon. R. I. J. Am. Chem. Soc: 2000. $22,1154$.

11. Gaussian 98. Revision A.7. Jirisch. M. J. et af. (jaussian. Inc. Pittsburgh. PA. 2002.

12. For a substitution elleet by anine donors on the tirst hyperpolarizability: (a) Whitaker. C. M.: Patterson. E. V.: Kott. K. L.: Mc. Vahon. R. J. J. Am. Chem Sor 1996. /18. 9966. (b) Park. G.: Rat C. S.: Cho, B. R. Bull. Korem Chem, Soc 2003, 24. 1671 .

13. For gas-phase substituent constant $\sigma_{\mathrm{vas}}$ see: Mishima. M.: Mustanir. M. F.: l'suno. Y. Bull. (hem. Soc. Jpn. 1996. 69. 2009.

14. Park. G.: Cho. B. R. J. Him Org. Chem. 2004. 17. 169.

15. (a) Park. G.: Ra. C. S. Bull Norwan. Chem. Soc 2003. 24. 1051. (b) Ra. C. S.: Kim. S. C.: Park. (i. J. Mtol. Stmot. (Theochem) 2004. 677. 173. 